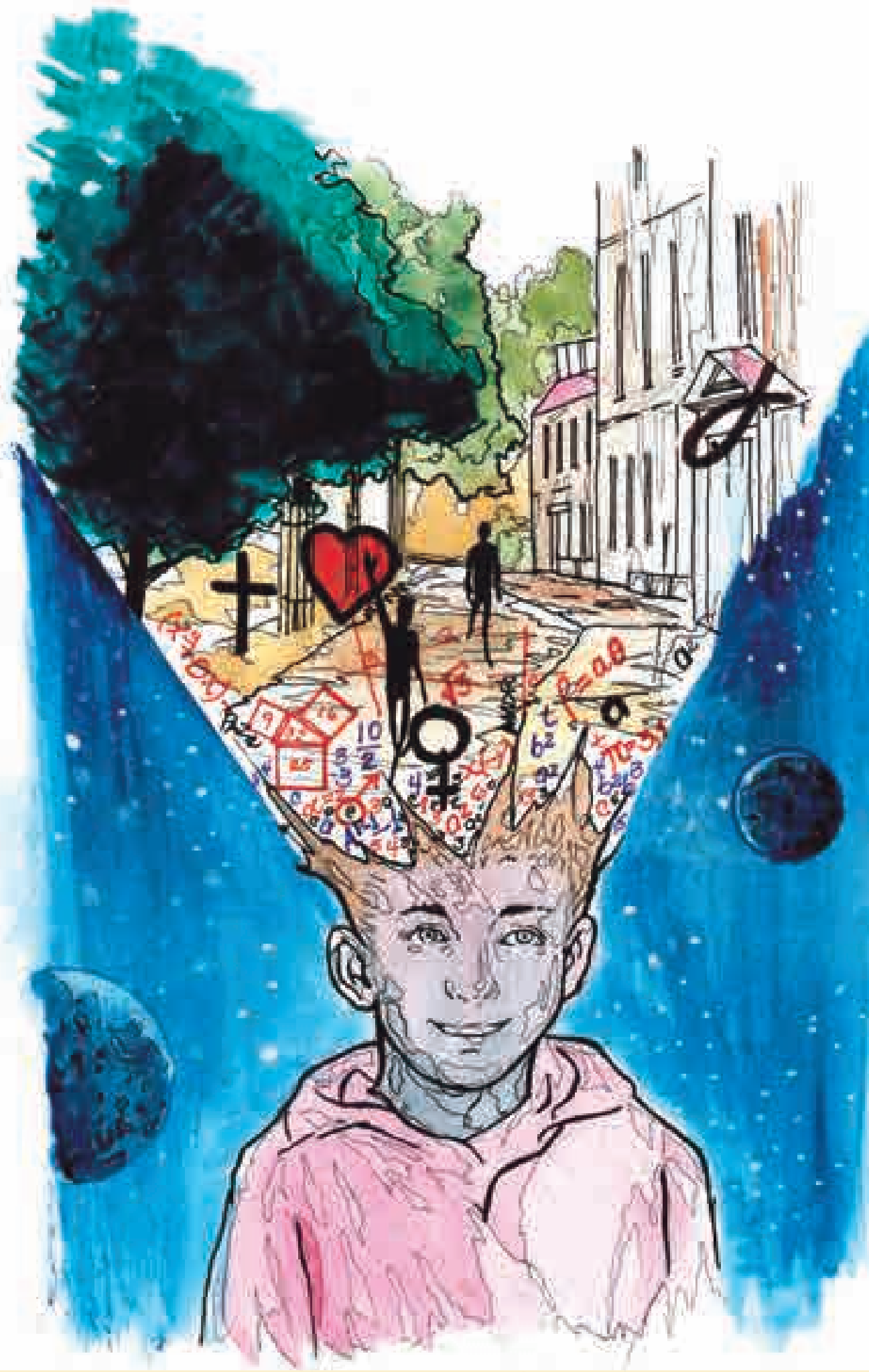

Ilustración 18. El día señalado llegó, el Aula Múltiple estaba a reventar, maestros de toda la comunidad dominicana, Universidad Santo Tomás, académicos e intelectuales se dieron cita para el encuentro educativo. Rubén Darío dio la bienvenida y el prior de la Orden de los Dominicos Fray Orlando Rueda, O.P. abrió el foro. 


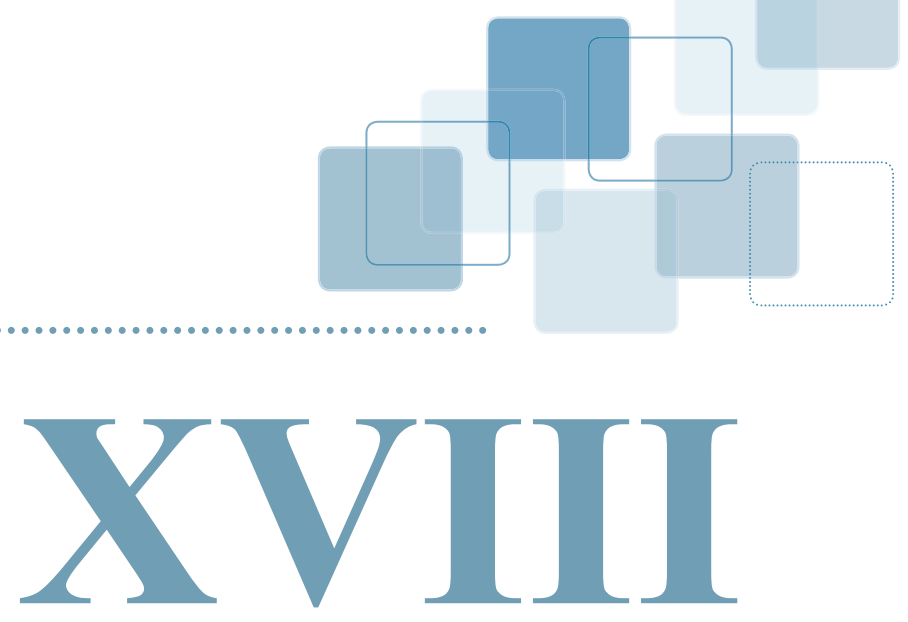

\section{LA INVENCIÓN JUVENIL DE LO COTIDIANO}

El afiche publicitario del Foro Educativo era una pieza muy creativa: Recreaba un aula de clases, una niña y un niño jugaban con un iPad mientras el maestro se desgastaba desde la pizarra para hacerse oír. El maestro estaba representado como un cavernícola, en su mano derecha tenía una tiza blanca y sobre la pizarra estaba escrito lo siguiente: ... De policías y ladrones a migrantes y nativos digitales: la invención cotidiana de la escuela. El folleto del evento también era un iPad, en tanto que la escarapela era un BlackBerry. El día señalado llegó, el Aula Múltiple estaba a reventar, maestros de toda la comunidad dominicana, Universidad Santo Tomás, académicos e intelectuales se dieron cita para el encuentro educativo. Rubén Darío dio la bienvenida y el prior de la Orden de los Dominicos Fray Orlando Rueda, O.P. abrió el Foro. Acto seguido, Fabián Sanabria se dirigió a los asistentes y dijo lo siguiente:

Cada vez que estoy en un colegio siempre se respira un ambiente muy especial y una de las cosas que más me llama la atención es el trabajo educativo, o más que el trabajo educativo, el quehacer educativo. Este nunca es suficiente, nunca vasta. Lo que hacemos es muy poco y siempre será muy poco, pero ese muy poco puede ser mucho. Me siento conmovido por dos razones: una, de lo que me he enterado de Isaac 
Herrera $^{15}$. En los griegos cuando un joven fallecía había que hacer luto. Ustedes están de luto... En segundo lugar, porque efectivamente, no somos profesores, ser profesor sería detestable, ser profesor es profesar, como dijo el padre provincial, y bueno... ojalá fuésemos maestros, eso es muy difícil porque a veces tenemos pretensiones muy grandes de enseñar y nosotros no enseñamos gran cosa, lo único que podemos hacer es aprender. Entonces, en ese horizonte es que quiero compartirles un poco esta reflexión.

Hay una característica muy concreta que el mundo contemporáneo... y es que una imagen vale mó qe mil palab as, ya no asociamos el creer al oír, ni el aprender está asociado con la mayoría de sentidos, sino que hemos reducido todo a lo que vemos, y lo que vemos es supremamente engañoso, esa es la gran paradoja del mundo que nos tocó vivir. Antes, por ejemplo, se creía en la palabra, hoy ya nadie cree en la palabra, hay un contrato firmado, no nos creen. Una imagen vale mó qe mil palab as, por todas partes y la mayoría de fotografías están 'photoshopeadas', es decir, nadie va a publicar su foto más fea en Facebook o en su hoja de vida. Entonces, es muy chistoso porque todos le creemos a las imágenes y las imágenes es lo que más nos engaña, es el mundo paradójico que nos toca vivir.

Hace un tiempo —podíamos hablar de 10, 20, 50, 100, 200 años y así hasta llegar a la Edad Media- había otros mecanismos a través de los cuales se creía y se aprendía. Hoy en día creemos es en lo que vemos, y lo que vemos, curiosamente es lo que más nos engaña, es una paradoja y dentro de esa paradoja estamos. Si ustedes me permiten hacer una paráfrasis: en la escuela o en el jardín, jugábamos a piedra, papel o tijera y ustedes se acuerdan que la piedra superaba la tijera porque la rompía, entonces uno dice, así como Coca-Cola mata a tinto, piedra mata a tijera y la tijera mataba el papel, porque lo cortaba y el papel mataba la piedra porque la envolvía, matab , en sentido muy colombiano. En el mundo contemporáneo estamos en un Universo, ya no de puentes, ni de puertas,

15 Isaac Herrera, estudiante tomasino, egresado en el año 2012, muerto el 08 de febrero de 2013. Fabián Sanabria se refiere a él, porque antes del inicio del Foro Educativo del 13 de febrero de 2013, sus compañeros y maestros le hicieron un homenaje póstumo. 
sino de ventanas, de Windows. Entonces, el juego que hay que hacer en vez de piedra, papel y tijera como reemplazo, un poco para variar ese puente y puerta, es la ventana.

Ahora bien, esto toca, por supuesto, a los sistemas educativos, no solamente a los sistemas religiosos ni a los sistemas políticos. En el mundo contemporáneo estamos participando de una sociedad cada vez más líquida, que se liquida con solo oprimir la tecla delete y todo se borra. Estamos asistiendo a una sociedad en donde ya no necesitamos desplazarnos hacia el otro, sino que desde una ventana donde algunos pretenden controlar el mundo, aunque hay millones que son desplazados por la guerra, por la pobreza, por la injusticia son las paradojas que se viven. Y aquí, dentro de los sistemas educativos, evidentemente tenemos que recordar cosas muy sencillas de los sistemas de enseñanzaaprendizaje, y es que una cosa es la representación de los objetos y otra cosa son los objetos.

El dibujo de una pipa no es una pipa ¿y esto por qué lo traigo a colación? Porque a veces confundimos las cosas de la lógica con la lógica de las cosas. Una cosa es lo que nos representamos del mundo y otra cosa lo que el mundo es. Entonces, nosotros lo que hacemos son cuadros de la realidad, pero el cuadro de la realidad no es la realidad. Felizmente, la realidad supera la representación que se hace de ella. Nuestro trabajo académico, científico es tratar de que el cuadro se aproxime lo más que se pueda a la realidad, pero sabiendo que la realidad siempre nos va a desbordar, sino nuestro trabajo ya estaría hecho y sería muy aburrido.

Y nosotros teorizamos mucho -los grandes pedagogos pues son teóricos-, pero justamente el reto es ¿cómo debe aprenderse la práctica, el terreno, lo concreto? Y muchas veces este terreno concreto ha variado. $\mathrm{Y}$ allí nos encontramos con una realidad que es muy importante y es que la misma concepción educativa, arquitectónicamente hablando, también tiene que cambiar ¿por qué?, por una razón muy sencilla. Ustedes me entregaron un BlackBerry -la escarapela-con mi nombre y una tableta con mi nombre -el folleto- y ustedes tienen todo eso... que algunos dicen: ¡ay! Es qe esos estudiantes no escuchn , pero es que ellos tienen el universo aquí - dijo señalando un Iphone. Entonces, el estatus de una persona que dizque sabe mucho, que se las sabe todas y que es regañón 
se vuelve aburrido con respecto al Universo que abre aquí para lo mejor y para lo peor, en error o en mentira o en verdad. Aquí (en la tableta) nadie lo regaña, aquí no hay: pórtese b en, pá ese b en, levát ese; aquí no lo regañan por mala ortografía, la permiten; aquí corta, copia y pega, ya no pueden expulsar a ningún estudiante por este motivo, porque todos lo hacen. Ya Wikipedia se volvió la enciclopedia, aquí los errores de Wikipedia se pueden corregir, los de la enciclopedia británica no, tienen que hacer otra nueva edición y no hay plata para hacerla. Y los errores, que a veces son mayúsculos, de Wikipedia, no son tantos como los de una enciclopedia impresa, eso ustedes ya lo han estudiado. Y la última palabra sobre el saber ¿quién lo tiene? Esa es una pregunta que también vale la pena formular.

En los sistemas educativos lo que podemos introducir -los profesores, o mejor,los maestros, yono sé cómo llamarlos-, principios de incertidumbre. $Y$ cuando uno reflexiona sobre el principio de incertidumbre, aparecen en el ser humano dos grandes fuerzas: la razón y el sentimiento. La razón nos produce verdad y el sentimiento nos produce consuelo. La razón nos produce una verdad lógica: $\$ \Phi$, la razón me produce una verdad matemática concreta y a veces muy cruda, puede ser que un ser querido se me muere, racionalmente nunca más lo voy a volver a ver, eso es una verdad... del polvo eres y al polvo volverír , espero que no hayan cambiado la fórmula. Del polvo eres y al polvo volveró es una verdad y me atrevo a decir que racional, concretísima, clarísima. Pero el sentimiento nos consuela, como uno no se conforma con esas verdades mortales, racionales, duras, entonces el sentimiento dice que de pronto van a comer galletitas con vino entre ángeles, arcángeles y serafines, tronos, dominaciones y potestades con el ser querido que falleció. Otros dicen que va a reencarnar en un conejo, entonces me consuela. Otros dicen que en el más allá, otros dicen que se va a aparecer... Ese es el sentimiento y la paradoja de esto es que la razón que me produce verdad no alcanza a hacer la verdad del consuelo, y el sentimiento que me consuela no alcanza a hacer del consuelo la verdad.

Entonces, cuando me doy cuenta de que la razón no alcanza a hacer de su verdad consuelo y de que el sentimiento que me consuela no alcanza a hacer de su consuelo verdad, se puede llegar al colmo de 
la razón que se llama escepticismo. Si soy muy racional, y se puede llegar al colmo del sentimiento que se llama desesperación, si solo y muy sentimental. Repito: la razón nos produce verdad, el sentimiento nos consuela, estas dos cosas se oponen en el hecho de que una niña se enamora de un muchacho y la mamá le dice ¿pero qué le ve a ese muchacho? Si es un vagabundo, no le van a dar trabajo, y la niña dice yo lo qi ero. Entonces, la razón que me produce verdad no alcanza a hacer de su verdad-consuelo, en oposición, el sentimiento que me consuela no alcanza a ser de su consuelo-verdad. Entonces, si yo soy muy racional llego al colmo de la razón que se llama escepticismo y si soy muy sentimental llegó al colmo del sentimiento, que se llama desesperación. Y paradójicamente, de esos dos colmos surge una fuente inagotable de verdad y de consuelo: la suprema incertidumbre.

La suprema incertidumbre es ¿y qué tal que sí? O ¿qué tal que no? Nosotros, como maestros, si es que lo podemos ser, eso sí, lo único que sí les suplico es que renuncien a la tentación de hacer el bien, porque nadie es bueno y, cuando alguien llamó al único bueno maestro be no él le dijo ¿por qué me llamas bueno si solo bueno hay uno? Entonces, maestros buenos no, por ahora no y que hagan el bien todavía no. Si llegáramos a ser maestros, en el mejor de los casos, lo que podemos hacer es introducir principios de incertidumbre, es decir, preguntas. El profesor que se las sabe todas, ese sí que es una caricatura y, que tiene que amenazar a los estudiantes con la nota y con la disciplina y con el rigor, ese es un pobre diablo, que está en el lugar equivocado y que es el hazmerreír clandestino de todos los alumnos.

Cuando uno se pregunta por la invención juvenil desde lo cotidiano y en lo cotidiano es ¿qué es ser joven? Es una pregunta que, desde hace tiempos, no mucho, a propósito, que se hace en las ciencias sociales y humanas y algunos establecen edad para determinar todo, otros dicen que el joven es inmaduro, otros dicen que el joven es el que escandaliza, entre otras cosas. Se ha nombrado un acuerdo muy funcional, esquemático para decir que alguien es joven, y ese acuerdo en sociología, es alguien que todavía no produce, ni reproduce, ni consume tanto y, sin embargo, 
es falso, porque hoy día hay jóvenes que trabajan y que pueden ganar más que un adulto. Por ejemplo, conozco a una cantidad de muchachos en los centros de alta tecnología nuestros, que son una caricatura, que es el chino con 14 años que dice uy profe, yo le arreglo el computador y se gana 12 millones de pesos y no es solamente en los Unilagos, sino en Bosa y en Ciudad Bolívar. Hay sitios en donde, tan grandes como un hangar, los padres y las madres de familia dejan al niño cacharriando entre computadores y no los llevan al jardín porque ahí aprenden más que en el jardín. Y entonces, producen y venden cosas, muchos estudiantes venden golosinas y algunos hasta se prostituyen para pagar su universidad, eso existe. Yo no les voy a hablar de un mundo que no existe, ni un mundo en una urna de cristal, eso no existe para mí.

Otros se reproducen, claro que sí -hay miles de embarazos adolescentes, eso no se ha acabado y hay una constatación de que cuando una joven queda embarazada y, pues ya, su vida cambió-. Claro, evidentemente depende del estrato, depende de la cultura... eso existe y ya se reproducen. Y consumen... hay un campo terriblemente adosado en donde los jóvenes están atrapados como en una red: el consumo, hay jóvenes que se sienten miserables porque no tienen la última camiseta, ni las últimas zapatillas, ni el último BlackBerry. Entonces consumen, producen y se reproducen, entonces no sirve el acuerdo sociológico de que no consumen, no producen y reproducen, ese acuerdo no sirvió.

¿Qué es ser joven? Otros hablan de la moratoria social en ese sentido de que todavía no producen, no reproducen y no consumen tanto, sí, pero resulta que había un gran caricaturista francés que nunca había dado la cara, pero que hacía reír a mucha gente y todo mundo dichoso leyendo sus comics. Entonces, alguien lo entrevistó, el entrevistador quedó estupefacto y le dice:

—...Pero no puede ser ¿usted es el que hace estos cómics?

—Claro, ¿cuál es el problema? El caricaturista era un señor de 80 años.

—Nosotros creíamos que usted era más joven... 
— ¿Quién dijo que yo no soy joven? Ser joven es no perder la capacidad de escandalizar...

Pero ser joven también es tener la capacidad de innovar, de vislumbrar y es terrible pensar en un mundo donde los jóvenes arrastran los pies ¿qué clase de mundo es ese?, un mundo donde los jóvenes están cansados ¿qué clase de mundo es ese? Un mundo donde los jóvenes se supone que son los del cambio, los de la revolución, los que trastocan paradigmas, los del anticonceptivo, los del rock, los de las tribus urbanas y son profundamente conservadores.

Entonces, los jóvenes interrumpen, construyen formas de ser, modos de sentir y de pensar y actuar, tienen sus estéticas, se pintan el pelo de morado y creo que ya en este país por la Constitución no pueden echar a un estudiante si se pinta el pelo de morado. En principio no, porque tutelan el colegio y eso cuesta caro. Entonces, los jóvenes evidentemente tienen apariencias, sexo, modos, estilos de vida, se ponen un arete... entonces que problema en nuestras instituciones educativas. Estos mismos jóvenes tienen una cosa maravilla, hay algo que sí aportan los jóvenes a nosotros los adultos, dizque sus maestros, y es que ellos tienen y están llenos de vitalidad, por eso digo que cuando los jóvenes no son vitales ¿qué clase de jóvenes son esos?

$\mathrm{Y}$ en buena medida, los jóvenes nos rejuvenecen. Un buen maestro siempre es joven gracias a que está rodeado de jóvenes, es como si los jóvenes nos chuparan saber y nosotros les chupamos juventud. Entonces la vitalidad en los jóvenes... Hay algo que hay que tener en cuenta y es que las manifestaciones juveniles muchas veces son percibidas como transgresoras, indisciplinadas, contrarias al orden, peligrosas, sobre todo cuando los medios de comunicación encuadran la sensualidad de los jóvenes y muchas veces sus manifestaciones violentas como un cóctel perfecto para tener mayor audiencia. Entonces lo que tenemos ordinariamente es la noción de las tribus urbanas y dentro de las tribus urbanas vamos a tener todos esos escenarios de violencia de los skinheads, de las barras bravas, de los emos que son tristes y los skinheads algunos los consienten y otros les cascan, los hppe rs con 
esos pantalones grandes y anchos, muchas veces destruyen el $b$ ue jean... ya lo venden así y es más caro. Entonces, el padre de familia no entiende por qué hay que comprar eso, pues hay que comprárselo.

Hay cientos de culturas juveniles, más que tribus urbanas, ¿usted cree que su estudiante cuelga el uniforme o sigue uniformadito en la casa? Aquí es donde se siente disfrazado. Obviamente, hay manifestaciones violentas que irrumpen en primera plana y entonces vienen a decir: nosotros no q eremos qe nuestros jóvenes sean asi y estos jóvenes pertenecientes a grupos neotribales, sin embargo, quieren ser actores y sujetos de la historia, no solamente, lo que yo llamo carne de cañón o banquete electoral. Carne de cañón es el servicio militar obligatorio que los niñs $b$ en no pagan porque eso es para los de ruana, salvo para el hijo del presidente que ese si lo paga y sale en todos los periódicos. Banquete electoral, pues evidentemente cuando los políticos van a hacer política a nuestros jóvenes es un gran banquete electoral, porque tan pronto voten este voto cuenta mucho. Entonces, más que de carne de cañón y banquete electoral, los jóvenes son mucho más que eso, son el futuro y sobre todo el futuro de un país descuadernado, que los adultos les dejamos y que los adultos debemos pedirle perdón por la clase de país que les dejamos.

Entonces, cuando estamos en la relación escolar, algunos dicen docente-dicente, profesor-estudiante, maestro-discípulo, es bella la distinción entre profesor y alumno y me gusta que el que profesa les repite a los estudiantes siempre con las mismas hojas amarillas de hace 40 años... y alumno el que no tiene luz... ¡qué horror!... usted tiene más luz que yo, usted tiene más vitalidad. Estamos asistiendo a procesos de descomposición y recomposición de las instituciones sociales, es decir, el sentido de lo social se cumple ahí plenamente, ya no puede darse ninguna institución. Cuando hablo de instituciones me refiero a Iglesia, Estado, familia, trabajo, escuela. Hay lugares en el mundo donde ya la gente quiere educarse sin escuela, hay iglesias, religiones, partidos políticos que se hacen y se deshacen y lentejos que pasan de uno a otro con todas las paladas y tajadas posibles. 
Ya nadie garantiza el amor hasta que la muerte los separe, ya nadie garantiza estabilidad laboral para siempre: contratos indefinidos. Entonces, el principio está escandalizado por la incertidumbre. Vivimos en un mundo incierto, un poco como decía San Pablo a tientas. Hay una parte muy bella de la misa, que me gusta, que es la plegaria eucarística y dice vuestra vida es como una tienda de campañ , una tienda de campaña es una cosa provisional, estamos de paso porque el mundo ha estado sin ustedes y va a seguir sin ustedes y no pasará nada. Descomposición y recomposición de las instituciones sociales, procesos feroces de racionalización económica en donde todo se mide con estándares y, eso va desde la ultra economía hasta el sufrimiento terrible por los centímetros de menos y los kilos de más. Entonces, en el mundo hoy lo que tenemos es un montón de niñas anoréxicas y muchachos vigoréxicos, enanos empaquetados y, del otro lado, niñas que inclusive van a vomitar lo que acaban de comer para mantener la línea.

No tenemos tiempo, todos vivimos corriendo y acelerados, pero al mismo tiempo podemos acceder supuestamente a todo. Exceso de espacios, pero ya no hay cama para tanta gente, es decir, paradójicamente el mundo se abre cerrándose. Se dice que las fronteras se diluyen, pero cada vez hay más fronteras imaginarias, ya no hay fronteras tan físicas, pero hay unos pequeños protocolos que simplemente no nos dejan pasar. Por ejemplo, a un inmigrante que quiere que le renueven la visa, simplemente le dicen: sí perfecto, escrib una carta pidiendo eso... en el idioma extranjero que no habla, entonces la persona termina llorando porque no puede... y se va. Hay miles de ejemplos donde evidentemente somos indeseables en no sé cuántos países, en donde nos piden visa; hay ciudadanos de primera, de segunda y de tercera... y algo que espero que se acabe con el nuevo aeropuerto es esas filas enteras para que nos forren las maletas en plástico, para que no les camuflen coca en el aeropuerto, como si no fuéramos dignos de nuestra maleta.

Nosotros, los maestros, tenemos que renunciar a la tentación de enseñar, en términos de profesar, de sabérnoslas todas, de dictar cátedra y más 
bien estemos todos dispuestos a aprender. En los sistemas educativos hay que aprender, hay que tratar de ser maestro en vez de ser profesor, que profesa verdades, y el alumno no es que no tenga luz. El estudiante es un buscador, es un errante e incluso es un inquieto que también le enseña al maestro. Algo que es muy importante es la comunicación, pero sobre todo, la conversación. Nuestras universidades, nuestros colegios se olvidaron de conversar y entonces nos la pasamos repitiendo fórmulas, aprendiendo categorías, haciendo cosas que nada tienen que ver con la vida, ni con la ciudadanía, que nada tiene que ver cuando uno está deprimido.

Bueno, preguntas que quedan ¿qué significa ser joven en el mundo contemporáneo? Una vez más los verbos tener, creer, vislumbrar, tener ganas para poder creer, para poder vislumbrar y crear. Hablo de un agnosticismo metodológico, es decir, que uno no se las sabe todas, y nunca está seguro de por dónde o cuál es el método, cuál es la teoría o la verdad adecuada. La verdadera vida es ausente, es decir, la vida está en otra parte y no en la academia, ni en el mundo de la escuela, porque nos hemos vuelto unas fábricas de competencias para cumplir estándares de calidad y llenar formatos y formularios que nos tienen hasta el cogote porque hay que cumplir las cosas.

El gran reto es ¿cómo lograr dejar de ser un burócrata de las competencias de los estándares? El mundo entero se llenó de eso y el pelado deprimido y el alumno se suicida... el papá lo está obligando a ser ingeniero y él quiere ser artista ¿qué estamos enseñando?, ¿cuál es nuestra misión?, ¿a qué le estamos apostando?, ¿se deben olvidar las costumbres para que haya una nueva escuela o se pueden retomar algunas para que sean usadas de manera conveniente?

La palabra moral viene del latín mores que quiere decir costumbre, pero las costumbres cambian, es decir, imagínese que hace treinta años era un delito para una mujer usar minifalda, la podían encerrar, hoy día no hay problema. Hace cien años los negros eran esclavos, las mujeres no contaban, los blancos burgueses eran los únicos que tenían poder, eso cambió. Los hombres no usaban pantalón, ni siquiera había ropa interior tan ergonómica como hoy, las costumbres cambian. 
Hay unas que se retoman otras no. Otros se apegan a las costumbres como si estuviera en las costumbres la verdad, pero la verdad es que las costumbres tienen historia y son arbitrarias muchas veces ¿por qué nosotros comemos con tenedores y no con palitos o con la mano? Si estuviéramos, por ejemplo, en la India o en un país árabe estaríamos sentados en el piso y si estuviéramos en Irak en un tapete persa y la disposición del salón sería otra. Entonces, las costumbres cambian, pero puede haber costumbres que alteran otras y son muy fuertes, pero por eso es que hay que viajar a lo largo del tiempo y el espacio para darse cuenta que el mundo cambia, que hay muchas cosas inimaginables. Por ejemplo, tener una tableta, un iPad... ya ni siquiera la computadora portátil... con la tableta. El computador es un portátil y lo abro cada mes, es más, ya todo lo manejo desde el celular y estos bichos van a hacer una cosa increíble. A futuro habrá aplicaciones donde uno se lo pone acá y le dice si el colon está irritado. Es definitivo, si la escuela no se adapta a los nuevos cambios, si no se sabe adaptar, queda out, queda por fuera y si el maestro no se adapta, queda out, queda por fuera, se va a volver señor que cree que los alumnos le aprenden, le hacen caso y está fuera de lugar, se burlan de él, no le tienen en cuenta, nunca se acordarán de él, es el hazmerreír de sus alumnos. Entonces, el mundo cambió para lo mejor y para lo peor.

Un atronador aplauso se escuchó en el recinto. La presentadora del evento invitó a los asistentes al refrigerio, mientras que Sanabria se quedó conversando con algunos de ellos. 
